\title{
Las Marcas del Linaje Diurno. Política, Límite y Justicia
}

\author{
The Marks of the Day Lineage. Politics, Limits and Justice
}

\begin{abstract}
María Cecilia Colombani ${ }^{1}$
${ }^{1}$ Profesora doctora de la Facultad de Filosofía, Ciencias de la Educación y Humanidades de la Universidad de Morón y de la Facultad de Humanidades de la Universidad Nacional de Mar del Plata. Investigadora de UBACYT de la Universidad de Buenos Aires. E-mail: ceciliacolombani@hotmail.com.
\end{abstract}

Recebido em 10 de junho de 2020; Aceito em 15 de julho de 2020

\section{Resumen}

Este artículo buscará pensar las figuras diurnas de un linaje que, desde Hesíodo a Platón, parecen encarnar la soberanía de la acción política que supone el ejercicio de la justicia como nota instituyente de la salud de la pólis ${ }^{78}$. Si bien la crítica se ha encargado de diferenciar los dos grandes poemas hesiódicos, a partir de los elementos que, efectivamente les son propios a cada una de las dos obras, nuestro modelo de interpretación de Hesíodo sugiere más continuidades que diferencias en lo que hace al análisis crítico de Teogonía y de Trabajos y Días. Creemos ver una línea de continuidad entre ambos y el sema que los vincula es precisamente el de la noción de justicia, inscrita en un horizonte de resonancias políticas y asociada a la idea de límite, ya sea en el gran escenario político de la dramaturgia divina o en la aldea hesiódica con la complejidad socio-política que acarrea la inminencia de la pólis.

Palabras clave: Hesíodo; Política; Grecia Antigua.

\section{Abstract}

This article will seek to think the daytime figures of a lineage that, since Hesiod to Plato, seem to embody the sovereignty of the political action that the exercise of justice supposes as an instituting note of the health of the polis. Although criticism has been in charge of differentiating the two great Hesiodic poems, based on the elements that are indeed specific to each of one of the two Works, our model of interpretation of Hesiod suggests more continuities than differences in what he does to the critical analysis of Theogony and Works and Days. We believe to see one line of continuity between both and the sema that links them is precisely that of the notion of justice, inscribed in a horizon of political resonances and associated with the idea of limit, either in the great

\footnotetext{
${ }^{78}$ El presente trabajo se encuadra en el proyecto de investigación que dirijo en el marco de la Secretaría de Ciencia y Técnica (SECYT) de la Universidad de Morón, proyecto radicado en la Facultad de Filosofía, Ciencias de la Educación y Humanidades y que releva la existencia de dos linajes, uno diurno y otro nocturno en la obra de Hesíodo y las proyecciones ulteriores que la idea de linaje como operador discurso permiten relevar.
} 
political scene of divine dramaturgy or in the Hesiodic village with the socio-political complexity that the imminence of the polis entails.

Keywords: Hesiod; Politics; Ancient Greece.

\section{Introducción}

Anticipando el arco de lectura, el filósofo platónico parece ser aquél que plasma el mismo imperativo hesiódico: dotar a la ciudad del sentido de justicia que fuera, tal como sostenemos, la preocupación del poeta beocio en Teogonía y en Trabajos y Días.

Hesíodo, luego del largo trabajo de linajes que presenta Teogonía, problematiza una cuestión más terrena. No en vano la consolidación de la pólis está cerca, y, en ese magma histórico aparece una serie de elementos germinales en el poeta beocio. Quizá sea Platón, en el marco de la configuración del filósofo gobernante, de la problematización filosófica del sujeto ético-político-estético y una prolija preocupación por el límite, el que termine poniendo en acto aquellos elementos solo esbozados y apenas vislumbrados en la obra hesiódica.

Ahora bien, los arcos de lectura suelen ser atajos extraordinarios para encontrar otros personajes, prácticas, configuraciones de pensamiento y leer las mutuas imbricaciones de los logoi. No solamente en el Platón ético-político se escuchan ecos de Hesíodo, ya que entre Hesíodo y él podemos relevar la figura de Apolo como aquel que sintetiza la noción de límite, de mesura, como contrapartida del exceso, advirtiendo la tensión hybris-sophrosyne. Par antitético del ulterior escenario ético-político y sin el cual es impensable la consolidación de una vida social atravesada por la justicia, que ya Hesíodo intuía y reclamaba, y que Platón necesariamente debe delinear como demanda epocal, a partir del desmoronamiento de la pólis.

Invitamos, pues, a recorrer esos atajos, esas sendas embrolladas, en sentido nietzscheano, para ver por dónde se dejan oír las voces lejanas que, a modo de ecos, la nueva narrativa de la ciudad recoge en su versión secularizada. 
El primer desplazamiento lo produce Apolo, reterritorializando la Dike universal en cada una de las nuevas ciudades. Se trata del Apolo fundador de ciudades, legislador, arquitecto espacial, conocedor de los límites, cuya demarcación permite la fundación de las poleis en el gran movimiento de colonización griega con el que los helenos despiertan de sus siglos oscuros.

El segundo desplazamiento se da en la figura del purificador. Es él quien, simbólicamente emparentado con el universo apolíneo, lleva la justicia a una ciudad impura, injusta, manchada por la sangre que derrama todo crimen y que encuentra en su figura lo que ha perdido. Las leyes de la ciudad hallan su fundamento en la Asamblea, mientras que la legalidad de la Grecia arcaica se descubría fuera de ella en el ámbito de lo divino, sin ir más lejos en la mítica figura del rey de justicia.

Cuando el orden ya no proviene del más allá, sino que es un asunto humano, la dimensión supra-humana se escapa. Para el hombre griego clásico sigue existiendo una dimensión de la vida que no puede aprehenderse. Precisamente, esto es lo que ha perdido la ciudad en el camino de la autonomía: la posibilidad de encontrar un orden, o de restaurarlo, en asuntos que exceden al control humano. Es este el enclave del podersaber de la figura del Purificador, que ya no será el fundamento del orden social, sino que solo intervendrá para restaurarlo cada vez que los hombres se desvíen de él. Tal como sostiene Vernant (1986, p. 55), "Será también, dentro del ámbito intelectual, un esfuerzo por trazar el cuadro y elaborar las nociones fundamentales de la nueva ética griega".

Platón realizará un tercer desplazamiento. Su preocupación será problematizar la constitución del sujeto ético-político, con lo cual el orden "desciende" y se encarna en el sujeto. Ya no es exclusivamente el orden cósmico de una legalidad que deriva del más allá. La nueva preocupación es la legalidad presente en el propio individuo, que sin dudas deberá ser acorde a la cósmica. 
En cada caso, la idea de límite sobrevuela el escenario, porque es precisamente la noción que constituye la bisagra que delimita lo cósmico de lo a-cósmico. Del Kosmos a la polis y de esta al sujeto. El bordado del linaje sigue operando con la misma vitalidad.

\section{El Gran Arquitecto del Límite. Apolo Territorio y Política}

Instalarse en la constitución del sujeto ético-político-estético entre los griegos, supone el desafío de desandar la huella que conduce a la sabiduría, lo cual nos lleva al lugar donde reina el Señor muy alto que naciera de Leto, a Delfos, sitio regio del Apolo legislador.

Apolo es el legislador por excelencia. No lo pensamos exclusivamente desde la frase canónica que lo identifica: "conócete a ti mismo", marca registrada de un conocimiento de la legalidad que nos atañe como sujetos. Lo es, más bien, a partir de su tarea cartográfica de demarcar los límites, de desmalezar los terrenos donde se habrán de fundar templos y ciudades, de bordar los contornos de un determinado territorio. Su expansión epifánica como divinidad abre a su paso una territorialidad que se asienta sobre las marcas del límite. Territorio y límite son la alianza que el señor de Delfos sostiene en su marcha por rutas y caminos, convirtiéndolo en un Apolo caminante.

Tales las huellas de un Apolo fundador de territorios. La tarea fundacional misma se apoya sobre el conocimiento del límite como elemento constitutivo de la demarcación territorial. El Apolo legislador deviene en función política. La fundación de las póleis habla de esa solidaridad que reúne las dos caras de un dios que nos tiene acostumbrados a las más diversas facetas.

Ahora bien, la propia tarea cartográfica implica una de "purificación" del territorio. El Apolo que impone los límites territoriales es el mismo que, con su acción, evita las mezclas, circunscribe los desórdenes, imponiendo la división como forma de conjurar el peligro. Trabaja por las formas puras, evita las confusiones tan propias de 
Dioniso, continuando la tarea iniciada por Hesíodo de aclarar los linajes, y anticipa la empresa platónica de purificar los conceptos.

Apolo es el que conduce por excelencia. La mántica orienta la tarea. Es un verdadero artista en el arte de conducir. La sentencia oracular despliega el camino. La gramática oracular, con su imperativo de mesura, inaugura la conducción hacia un tópos moral que no puede visualizarse sin la presencia de la divinidad, en tanto dadora de sentido moral. La mesura es el hilo que conduce la actividad, es el preciado logro que Apolo invita a plasmar, aunque él mismo se muestre desmesurado. Toda la ética griega tendrá esta impronta apolínea ya que la constitución del sujeto moral parece quedar territorializada en los límites que marcara el conductor. El agonismo ético no es otra cosa que el viejo ágon (combate) que el hombre libra con la divinidad en su más radical disimetría ontológica.

Esa es la más sabia de las conductas del hombre: demarcar los territorios de la acción prudente y de la acción desmesurada. Saber elegir, preferir, resolver el camino, juzgar lo correcto de lo incorrecto, condenar una vida desordenada.

\section{El Purificador y la Nueva Versión del Límite}

El siglo VII constituirá un escenario de profundos cambios socio-económicas, de directo impacto sobre las costumbres y los modelos de comportamiento. Tal como sostiene Albin Lesky (1966, p. 184):

Éstos no sólo se efectuaron en el dominio económico y político; a la aparición de nuevas capas sociales correspondían cuestiones religiosas y necesidades que ya no lograba satisfacer el mundo homérico. Desde que abandonamos éste, observamos una mayor diferenciación en las expresiones del espíritu griego.

Es precisamente esa falta de respuesta lo que determina un cambio de esquema mental; un nuevo logos como forma de encastre de las palabras y las cosas. En ese 
ISSN 1982-8713

magma instituyente de lo nuevo, esa agitación religiosa constituye un enclave fundamental en la organización moral de la pólis; es allí donde retorna la problemática del límite.

Podemos recoger el dato de Jean Pierre Vernant $(1986$, p. 55$)$ al respecto para consolidar la ecuación entre crisis y efervescencia religiosa:

Através de una mezcla de datos puramente legendarios de alusiones históricas, de sentencias políticas y de esquemas morales, la tradición más o menos mítica de los Siete Sabios pone a nuestro alcance y nos permite comprender un momento de la historia social. Momento de crisis, que se inicia a fines del siglo VII y se desarrolla en el siglo VI, período de turbulencias y conflictos internos, de los cuales percibimos algunas condiciones económicas y que los griegos vivieron, en un plano religioso y moral, como una puesta en cuestión de todo su sistema de valores, como un ataque al orden mismo del mundo, como un estado de falta y de impureza.

Quizás, una falta de límite. En este enclave, la figura de Epiménides de Creta se erige, como la más significativa y la más cercana a la dimensión de la purificación que queremos solidarizar con la noción de límite. En efecto, las consecuencias de la crisis traerán distintas reformas tanto en el dominio del derecho, como de la vida social y es allí donde un purificador como Epiménides, un legislador como Solón, un asimnetes como Pítaco, cobran relevancia.

No obstante, más allá de este propósito, queremos ubicarlo en el concierto amplio de una serie de personajes que dan cuenta de la aludida conmoción religiosa; figuras envueltas en leyendas que, en todos los casos, hablan de poderes y posiciones excepcionales y extra-ordinarias como notas antropológicas constitutivas.

No obstante, el planteo vuelve a ser genealógico. El tema es ver cuáles son las condiciones de posibilidad para la emergencia de ciertos personajes. Así: 
El esfuerzo de renovación actúa en distintos planos a la vez: es simultáneamente religioso, jurídico, político y económico; aspira siempre a restringir la dynamis de los gene, quiere poner un límite a su ambición, a su iniciativa, a la voluntad de poder, sometiéndolas a unas regla general cuya obligación se aplique por igual a todos (VERNANT, 1986, p. 59).

La ambición de poder es exactamente la transgresión del límite comunitario que parece ser el nuevo credo de la pólis; es por ello que la preocupación por la norma superior, que no es otra cosa que la dike, viene a garantizar la xeunomía, "la distribución equitativa de las obligaciones, de los honores, del poder, entre los individuos y las facciones que componen el cuerpo social" (VERNANT, 1986, p. 59). Cuestión de límites en la medida en que cada elemento que constituye el kosmos social ocupa el lugar que le corresponde.

Asistimos a realidades que se mezclan, a sendas embrolladas que trazan un espacio de indefinición, rico y plural en matices que devuelve, por ejemplo, en un mismo siglo, el VI, la incipiente filosofía naturalista y a un Aristeas de Proconeso, de quien Heródoto cuenta que en una ocasión cayó muerto en su patria, pero al mismo tiempo lo vieron vivo en otros lugares muy distantes. La leyenda lo perpetúa en el marco de viajes que lo trasladan al norte en éxtasis apolíneos. Más allá de la imposibilidad del dato histórico, lo que parece significativo es el clima religioso de la época: "Lo que se nos relata del hombre cuya alma, según una nota de la Suda, podía abandonar el cuerpo a su antojo, que en estado delirante hacía maravillosos viajes y ocasionalmente adoptaba la forma de animal, procede de la esfera del chamanismo" (LESKY, 1966, p. 185). En última instancia asistimos a los vínculos entre el chamanismo y Apolo, entre el país de los Hiperbóreos y ciertas figuras extraordinarias asociadas al fenómeno apolíneo que parecen trazar un arco de proximidad entre el mundo escita y la Grecia Antigua.

En este marco, otra figura de singularidad antropológica es Ábaris, un hiperbóreo que viajó por todo el mundo llevando una saeta. Como a Aristeas se le atribuyó una 
Teogonía en prosa, lo que nos lleva a suponer la existencia y circulación en la época, de este tipo de literatura religiosa. Y aquí un dato importante a nuestra línea de trabajo, sostenida por Lesky (1966, p. 185): "En la medida en que es posible hacernos una idea, vemos que, si bien tienen muchos elementos propios, no dejan de apoyarse por ello en la tradición de Hesíodo. No sólo pretenden hablarnos de los dioses, sino que aspiran también a ser cosmogonías".

Quizá podamos intuir que en estas teogonías y cosmogonías se está dando la circulación de un tipo de logos que, como en la versión hesiódica, busca limitar las posibilidades del khaos. Una teogonía, en tanto relato de dioses, y una cosmogonía, como relato del orden, no hacen sino sentar las bases del límite mismo de lo cósmico.

Finalmente, nos encontramos con Epiménides como figura rectora de este tipo de personaje, a quien Marcel Detienne no duda en calificar como un maestro de verdad (DETIENNE, 1986). A él se le atribuye una Teogonía de cinco mil hexámetros, como asimismo, haber sido el purificador de Atenas tras la profanación cilónica. También esta figura está asociada a relatos legendarios de experiencias excepcionales, suprahumanas, como largos períodos de sueño que lo emparientan con los personajes anteriores. Tal como señala Lesky (1966, p. 185): “También circulaban bajo su nombre poemas expiatorios y oráculos. Estos últimos son parte de una transmisión que creció poderosamente en el siglo $\mathrm{VI}^{\prime \prime}$.

En este punto debemos detenernos para ajustar las relaciones entre una figura como la de Epiménides y la cuestión del límite, asociado con la capacidad de poner fin a la mancha que acarrea la transgresión. Tal como sostiene Vernant: "En la línea de esos magos purificadores, la figura de Epiménides se destaca con particular relieve" (1986, p. 60). Los motivos de tal peculiaridad se deben a que es un sabio en cuestiones divinas, poseedor de un tipo de sabiduría entusiástica e iniciática, tal como refiere Plutarco, quien agrega precisamente la referencia histórica de ser él a quien Atenas debe llamar para sacar de su ámbito el míasma que la atraviesa luego del asesinato perpetrado. 
Se trata por tanto de un maestro de aletheia, en tanto sujeto excepcional capaz de un don de videncia que lo lleva a de-velar, des-ocultar aquello que se escapa a una visión ordinaria. Vernant recurre a Aristóteles para devolver su pintura:

Promotor de ritos catárticos, es también un adivino inspirado cuyo saber, nos dice Aristóteles, descubre el pasado, no el futuro; sus don de doble vista descubre, efectivamente, las faltas antiguas; devela los crímenes ignorados cuya impureza engendra, tanto en los individuos como en las ciudades, un estado de perturbación y de enfermedad, el delirio frenético de la manía, con su cortejo de desórdenes, de violencias y de asesinatos (VERNANT, 1986, p. 60).

La caracterización es interesante en más de un sentido: mirar lo acontecido es la única manera de saber qué es lo que ha manchado a la ciudad porque el asesinato aparece como una mancha que se derrama al infinito; que se extiende contaminando personas, familias y ciudades en su conjunto. Solo una mirada de lo que fue, a partir de esa especie de omnisciencia que la Memoria sacralizada otorga, devela, des-oculta, descubre, quita el velo de lo velado y de lo que daña a la comunidad toda. Esa visión de lo acontecido, y que ha quedado silenciado y oculto tras el velo de Lethe, puede restaurar el orden y poner límite a la mácula. Un purificador capaz de ver lo que fue goza de un tipo de Memoria que dista enormemente de la memoria como facultad humana; se trata de la ciencia de Mnemosyne, de aquella excepcionalidad en la que "la memoria es una omnisciencia de carácter adivinatorio; defínese, como el saber mántico, por la fórmula: "lo que es, lo que será, lo que fue'” (DETIENNE, 1986, p. 26).

El segundo elemento se inscribe en la metáfora médica. Medicina, purificación y acción política aúnan matices. La ciudad se ha enfermado por las faltas antiguas y el velo del Olvido y el Silencio ha sepultado los antiguos crímenes. La enfermedad está asociada a la falta de límite porque nadie ha podido acotar y poner fin al míasma desatado; la hora de un sanador se impone debido a que solo a partir de su visión-acción catártica, 
de su saber-poder inscrito en la excepcionalidad antropológica que lo distingue, llegará el remedio que no es otro que la imposición del límite correspondiente.

La noción de míasma abre un escenario rico en matices, ya que en ella se cruzan vínculos semánticos que rozan tanto al crimen como a la enfermedad y dan cuenta de la duplicidad estructural de la noción: mancha, mancha de sangre, infección, impureza, infamia, crimen.

Epiménides opera como un sanador en el sentido de un restaurador. Un purificador es un restaurador en la medida en que restablece los límites subvertidos; reacomoda los topoi alterados y circunscribe el orden cósmico en el punto en que fuera dañado. Un purificador sana la a-cosmicidad provocada reconociendo que el peligro que lo a-cósmico entraña solo puede ser resuelto por un sujeto excepcional. Y esto constituye una tarea de efecto político. Coincidimos con Vernant (1986, p. 60) cuando afirma: "En el fondo se trata, en ambos casos de una actividad orientada en el mismo sentido y que aspira a ordenar la vida social, a reconciliar y unificar la ciudad".

Es la misma ciudad en su institución la que reclama figuras de esta condición. La institución de la pólis necesita cierta acción política tendiente a lograr la unificación del cuerpo social como cuerpo orgánico y por ello la figura de Epiménides es solidaria de la de Solón. La habrosyne ha dañado severamente a la sociedad griega y el esfuerzo moralizador es proporcional al daño engendrado. Es en esta línea que Plutarco recupera, una vez más, su figura cuando sostiene que al haber santificado y consagrado a la ciudad a través de los ritos expiatorios y purificadores, logró que la mismísima pólis se vuelva obediente al derecho y más fácil de persuadir (PLUTARCO. Vida de Solón. XII, 7-12).

Esta es la dimensión política que rescatamos de dichas figuras: su capacidad de operar sobre la realidad generando cambios y transformaciones en lo real mismo. Es este el punto donde el saber que portan adquiere una dimensión política en tanto mecanismo operador de verdad. 
ISSN 1982-8713

De allí nuestro interés en ir más allá del relato legendario, pintoresco y peculiar de cierto tiempo histórico. Se trata más bien de inscribir a estas figuras en un proyecto político-terapéutico de transformación de la sociedad en su conjunto. En cierto modo, tiene que ver con pensar en una voluntad de verdad, en una reunión de fuerzas que operan para producir algún efecto posible.

La ciudad es el medio de producción de estas figuras, que, como siempre no pueden ser leídas por fuera de sus condiciones posibilitantes. Coincidimos con Vernant (1986, p. 63) cuando sostiene que:

Los diferentes rasgos que los griegos han agrupado para componer la figura de un Epiménides no constituye un elemento aislado. Un personaje como Abaris - que se inscribe con otros magos: Aristeas, Hermótimo, en la tradición legendaria del pitagorismo- no es solamente un chamán que vuela por los aires con su flecha de oro, que vive sin alimentarse y que envía su alma a vagar lejos del cuerpo; es, a la vez que un cresmólogo, un reformador religioso y un purificador; funda, dentro del marco de religión pública, ritos nuevos: en Atenas, los Proerosia; erige santuarios protectores de la comunidad: en Esparta, el de Kore salvadora; instituye procedimientos catárticos que permiten a los ciudadanos impedir el desencadenamiento de un loimos.

Esta es siempre la amenaza, la peste, la epidemia, que la ausencia de límite ha traído o puede siempre traer.

\section{El Filósofo Gobernante y la Definitiva Plasmación de la Relación Límite-Justicia}

"La efervescencia religiosa no contribuyó solamente al nacimiento del Derecho. Preparó también un esfuerzo de reflexión moral y orientó especulaciones políticas" (VERNANT, 1986, p. 65) Nuestro atajo nos ha llevado a pensar distintas figuras vinculadas a la noción de límite. 
Haremos, por tanto, una mención inaugural para Hesíodo y su aspiración por el orden como forma de imponer límite a la indefinición cósmica o social, a partir de la dramaturgia divina de Teogonía o de las consideraciones ético-políticas de Trabajos y Días.

Una segunda mención a Apolo, el gran arquitecto del límite, el señor que reina en Delfos, precisamente en ese templo que construyera luego de preparar el terreno, de civilizarlo, marcando el espacio salvaje devenido en territorio apto. Gesto arquetípico de lo que constituye instituir los límites cuando la gesta así lo impone.

Una tercera mención a la figura de Epiménides y en ella, en realidad, a una construcción social que ve en la figura excepcional del purificador al sujeto capaz de imponer el límite que la ciudad ha perdido a causa de su desvío.

Queremos transitar por una nueva figura; tomar un nuevo atajo y pensar la Filosofía a la luz de cierto mandato apolíneo para resguardar las líneas de continuidad del presente proyecto. Considerar la figura del filósofo en la narrativa platónica a la luz de cierto escenario familiar, pensando la necesidad manifiesta de la sociedad griega de sanear sus estructuras dañadas.

Quizá convenga iniciar el recorrido por el "conócete a ti mismo", expresión que se recorta de un fondo religioso y que vehiculiza toda acción conforme a areté. Develar la semántica oracular equivale a asumir la misión encomendada por el dios y hacer de la filosofía un verdadero ethos, un estilo de vida acorde, esto es, a la justicia, al conocimiento. Ahora bien, el primer elemento de esa exhortación se vincula con la noción de límite porque constituye la invitación a pensar el propio límite de lo humano frente a lo divino. El "conócete a ti mismo" es un imperativo de mesura. Que la ulterior narrativa haya hecho de la máxima un topos múltiple de interpretaciones, todas inscritas en la larga "historia de la espiritualidad en Occidente", no invalida esa primerísima 
exhortación apolínea a saber, que no somos dioses ni nunca lo seremos (FOUCAULT, $1997)^{79}$.

El segundo elemento consiste en observar la máxima apolínea a la luz del desafío supremo de la Filosofía, esto es, alcanzar la verdad como objeto último de deseo, como mayor dignidad ontológica, porque con ese hallazgo la ciudad puede ser saneada de su resquebrajamiento. La misión encomendada supone un punto de llegada: alcanzar el Bien dentro de una lógica que ha desplazado el marco religioso y que, en su utopía secularizada, encumbra la Idea en el lugar de la máxima luminosidad. Por eso, en el Platón pedagogo, aquél que no escatima esfuerzos didácticos en la suprema y compleja explicación de lo que es el Bien, el sol es el vástago del "Bien en sí". Propone la alegoría como recurso ad-hoc. La aventura filosófica no es otra que la sabia decisión de alcanzar "to on" y "aei on", "lo que verdaderamente es" y "lo que siempre es". Y esta tarea comprometa una cartografía del límite, un ingente trabajo de desmalezar el terreno de todo aquello que atente contra el hallazgo.

Sócrates presenta su proyecto cuando advierte a sus discípulos, haciendo hincapié en la dificultad de la empresa:

Creedme, queridos amigos, dejemos por esta vez la indagación del bien tal como es en sí, pues me será muy difícil explicaros su naturaleza, tal como yo la concibo, siguiendo el camino elegido. En cambio, estoy dispuesto a hablar de lo que me parece ser hijo del bien y que mucho se le asemeja (Platón. República. 506-e).

El Bien, como final de un largo camino teleológico, implica la misma ruta de contorneo, los mismos atajos de develamiento y descubrimiento, ahora sostenidos por la retórica dialéctica y la elección alegórica. En la base, la misma metáfora lumínica que

\footnotetext{
${ }^{79}$ La hermenéutica del sujeto despliega lo que él interpreta como la larga "historia de la espiritualidad en Occidente", esto es el camino que supone, por parte del sujeto, el acceso a la verdad. Se trata, entonces, de ver cómo en las sociedades occidentales pre-modernas, el acceso a la verdad, como objeto prestigioso de llegada, supone un cierto camino de disciplinamiento que compromete la vida entera de los sujetos. Sobre este tema, puede verse Colombani (2009).
} 
ha aparecido explícita o implícitamente en otros segmentos del presente trabajo; la idea de la luminosidad que sabrá conducir esas almas erráticas y embriagadas que, sin luz, equivocan el camino de la verdad y la prudencia, porque desconocen el límite entre lo claro y lo oscuro, lo verdadero y lo aparente. Solo quien obedece al lógos apolíneo y hace de la filosofía una forma de vida anuda la solidaridad entre obrar y pensar y sostiene el enlace entre conocimiento y acción porque conoce el fundamento del obrar justo.

Cuando Platón delinea el perfil del filósofo gobernante y despliega su metáfora médico-política, alude a que el guardián deberá mostrar su amor a la pólis. La forma más acabada de obrar políticamente, con rectitud, está emparentada con la idea de límite: obrar bien es obrar verdaderamente, hacerlo en nombre de la verdadera filosofía y esto supone poner límite a toda forma de la filosofía no verdadera. El límite es preciso y siempre tensiona los mismo topoi, a saber, el campo de ta alethea y el de ta pseudea, como terrenos de distinta categoría ontológica.

La forma más perfecta de brindar su amor a la pólis es devolver a la ciudad aquellas cosas útiles que contribuyan al bien común: "cosas buenas", "cosas bellas", "cosas justas". Y la única manera de sostener semejante función, del más puro rango de la luminosidad, no puede darse si no se conoce el fundamento, aquello que hace que todo lo bueno sea bueno, que todo lo bello, bello, y que todo lo justo, justo. Conocer el fundamento, la arkhe, como razón explicativa de aquello que es, es alcanzar ese punto máximo de luminosidad desde donde parte toda claridad posible. Es conocer el límite mismo de lo real, para no confundir los topoi que deben permanecer distinguidos.

Claridad no solo en el orden del ser, sino en el registro del conocer. Y aquí también la idea de límite retorna con fuerza inusitada. El verdadero conocimiento es aquel que pone límite a la opinión. La retórica es siempre la misma: el filósofo purifica los topoi, dotando a cada cosa con su lugar específico y evitando toda contaminación del orden. Sócrates sostiene este conocimiento cuando afirma: 
Pienso yo, en efecto, que las cosas justas y bellas no hallarán un guardián digno en aquel que ignore su relación con el bien, y conjeturo que nadie podrá tener un conocimiento exacto de estas cosas sin el previo conocimiento del bien. (...) Y no estará nuestro régimen político perfectamente organizado si vela por él un guardián que una el conocimiento del bien al de lo bello y lo justo? (Platón. República. 506-b).

La Idea es la condición de inteligibilidad y de existencia de todo lo bueno y lo justo. Esta narrativa se sostiene desde el orden de la luminosidad y es la propia aletheia la que resplandece en el fondo mismo de la configuración del ser, el pensar y el obrar, del mismo modo que resplandece el sol en el fondo de lo visible. En la alegoría del Sol el Bien en sí, que reina en el ámbito inteligible, como el Sol lo hace en el sensible, dona la verdad como condición de posibilidad para que las ideas puedan ser inteligidas; la verdad opera como una especie de luminosidad para que las realidades en grado sumo, las ideas, puedan ser pensadas. Así se expresa Sócrates cuando afirma: "Pues ten en cuenta que me refería al Sol cuando hablaba del hijo del bien, que éste engendró a su semejanza y que, en el mundo visible, con relación a la vista y a los objetos visibles, es análogo al bien en el mundo inteligible con relación a la inteligencia y a los objetos inteligibles o pensados" (Platón. República. 508-b).

No solo la metáfora lumínica aparece sosteniendo el recurso alegórico; la idea del viaje es clave a la hora de comprender la tarea platónica: de un ámbito a otro, el alma se prepara para distinguir las realidades más perfectas y así conocer el límite preciso que separa los distintos registros de ser y conocer. Este es el camino de quien podrá gobernar la pólis en una tarea que supone conocer el pharmakon para curar el mal. Una ciudad enferma requiere el mejor iatros y la utopía platónica ubica al filósofo en ese lugar de la cura. 
ISSN 1982-8713

\section{Conclusiones}

La vieja sofía se ha trastocado en filosofía, pero una misma metáfora lumínica que aboga por la evidencia del límite, condición de posibilidad de un orden justo, parece guiar un camino que busca afanosamente evitar la oscuridad temida, la forma de caer en las tinieblas y en el olvido, nítida injusticia, transgresión del límite.

El Apolo artista delineó las sendas a develar, tanto en su dimensión de caminante, como en la narrativa oracular que lo distingue; desplegó las artes de un camino que el hombre prudente debe poder transitar para alcanzar la mesura y mantener el límite-justicia de sí mismo y de la ciudad. En realidad, no hay distancia entre el sujeto y la pólis en el registro de la mesura. El purificador transitó la senda apolínea y fue capaz de sanear las impurezas de una ciudad que había caído en la falta.

El filósofo habrá de ser un nuevo artista, un nuevo conductor en ese arte de recorrer un methodos, alguien que sabe de las dificultades de deambular por las alturas. La nueva estética supone transitar por los mathemata (estudios) como forma de preparar el alma para la más sublime de las miradas. Disciplina, ejercitación, entrenamiento, askesis. He allí el legado oracular que retorna, una y otra vez, tanto en la constitución del sujeto ético-político-estético, donde se anudan en una magnífica sinfonía el "conócete a ti mismo" y el "nada en exceso", como en la más fina construcción del ideal del filósofo.

Sostenemos que el filósofo es la nueva figura que el linaje diurno, aquel terreno magistralmente preparado por el Hesíodo genealogista, encumbra en el lugar de las alturas. De un modo semejante a Apolo, o al purificador, el filósofo constituye una nueva "versión" de antiguos "ecos"; el nuevo maestro de verdad, en la retórica de Marcel Detienne, el pretendiente a conducir los destinos de la polis bajo los signos de la aletheia, será el mejor de los fulakes, aquel que sepa guardar el límite, evitar las contaminaciones, conjurar las mezclas, discriminar los territorios, cuidar las fronteras entre lo puro y lo impuro, preservar los linajes. El escenario de la acción no es otro que 
el alma como topos agonístico, ya que, su territorialidad ambigua, con sus regiones delimitadas, transidas por los diferentes registros de racionalidad, exige un guardián más que atento.

Apolo, el sutil arquitecto de los templos y de las conductas mesuradas; maestro en el arte de conducir una vida conforme a límite y conocimiento, parece ser el vicario mítico de un largo relato de perfil ascético recuperado por distintas tradiciones.

Apolo esteta, señor de las artes, que desde su altura traza un camino devenido en agon. Caminante y constructor; señor de las rutas que se abren para fundar templos y ciudades y de los trazos morales para fundar vidas conforme a medida. Es, sin duda, el antecedente mítico de un nuevo maestro de verdad: el filósofo. Hábil en el arte de conducir tanto la propia vida como la de los otros; el filósofo, ese nuevo artista que la pólis necesita en su gesta instituyente, capaz de hilvanar los hilos de una trama que no cesa de renovarse: disciplina y conocimiento, askesis y mathesis, como condición de posibilidad del nuevo orden.

Claro que la metáfora retorna en el premio más codiciado. Sócrates tarda en decirlo, pero su discípulo escucha lo previsible: "En realidad, querido amigo no me animaba a decir lo que al fin he decidido declarar, pues ha llegado el momento de que señalemos que los más perfectos guardianes de la ciudad deberán ser los filósofos" (Platón. República. 503-b).

\section{Bibliografía}

COLLI, Giorgio. El nacimiento de la filosofía. Barcelona: Editorial Tusquets, 1987.

COLLI, Giorgio. La sabiduría griega. Valladolid: Ed. Trotta, 1988.

COLOMBANI, María Cecilia. Hesíodo. Una introducción crítica. Buenos Aires: Santiago Arcos, 2005.

COLOMBANI, María Cecilia. Foucault y lo político. Buenos Aires: Prometeo, 2009. 
CORNFORD, F. M. From Religion to Philosophy. New York: Harper Torchbook, 1957.

CORNFORD, F. M. Principium Sapientiae. Ed. Visor Distribuciones, Colección "La balsa de la Medusa", n 6, Madrid, 1987.

DETIENNE, Marcel. Los maestros de verdad en la Grecia Arcaica. Madrid: Editorial Taurus, 1986.

EGGERS LAN, Conrado. Introducción histórica al estudio de Platón. Buenos Aires: Ed. Colihue, 2000.

EGGERS LAN, Conrado. El sol, la línea y la caverna. Buenos Aires: Editorial Universitaria de Buenos Aires, 1975.

FOUCAULT, Michel. La hermenéutica del sujeto. La Plata: Altamira, 1997.

GERNET, Louis. Antropología de la Grecia Antigua. Madrid: Editorial Taurus, 1981.

GIGON, Olof. Los orígenes de la filosofía griega. Madrid: Ed. Gredos, 1980.

HESÍODO. Obras y fragmentos ("Los trabajos y los días" y "Teogonía”). Madrid: Ed. Gredos, 2000.

JAEGER, Werner. Paideia. México, DF: Fondo de Cultura Económica, 1995.

LESKY, A, Historia de la literatura griega, Barcelona: Labor, 1966

MONDOLFO, Rodolfo. El pensamiento antiguo. Buenos Aires: Ed. Losada, 1980

NILSSON, Martín P. Historia de la religiosidad griega. Madrid: Editorial Gredos, 1969.

PLATÓN. República. Buenos Aires: Editorial Universitaria de Buenos Aires, 1963.

PLUTARCO, Vidas Paralelas II. Madrid: Gredos, 2001.

VERNANT, Jean Pierre. Los orígenes del pensamiento griego. Buenos Aires: Ed. EUDEBA, 1986. 